\title{
Tratamento cirúrgico da miopatia fibrótica - relato de caso
}

Ivens Navarro Haponiuk Prus ${ }^{[]^{*}}$, Enio Augusto Granatto de Oliveira ${ }^{[b]}$, Luane Camargo Zeni[a], Andressa Batista da Silveira[c], Luciana Doria Ribeiro Cabral[a]

\author{
[a] Pontifícia Universidade Católica do Paraná (PUCPR), Curitiba, PR, Brasil \\ ${ }^{[b]}$ Regimento de Polícia Montada Coronel Dulcídio (RPMON), Curitiba, PR, Brasil \\ ${ }^{[c]}$ Universidade Federal de Minas Gerais (UFMG), Belo Horizonte, MG, Brasil
}

*Autor correspondente

e-mail: ivenshaponiuk@gmail.com

\section{Resumo}

A miopatia fibrótica, doença degenerativa que atinge principalmente equinos da raça Quarto de Milha, afetando comumente os membros pélvicos do animal, caracteriza-se pela formação de uma fibrose ou ossificação do músculo, causada por ações traumáticas que evoluem para uma ruptura de feixes musculares. Acometem principalmente os músculos semimenbranoso e semitendinoso, podendo estes aderirem-se e limitar a sua movimentação, alterando o andar. A formação da fibrose é facilmente identificada durante a palpação pelo desenvolvimento de uma massa de consistência firme. A alteração no passo do animal e o auxílio do exame ultrassonográfico e radiográfico da região são métodos que colaboram no diagnóstico da doença e da região afetada. Com isso, a intervenção cirúrgica é recomendada. Um equino macho, mestiço, 17 anos, utilizado no patrulhamento montado, foi atendido na Unidade Hospitalar de Equinos - PUCPR apresentando claudicação do membro posterior esquerdo (MPE). Ao exame clínico, constatou-se claudicação mecânica ao passo, sendo possível observar que o paciente não executava a fase cranial do passo, fazendo com que o membro acometido fosse abruptamente puxado para trás. Durante a palpação, notou-se uma massa de consistência rígida na porção caudal da coxa do MPE. Ao exame radiográfico da região do glúteo, não foi observada alteração, porém, ao exame ultrassonográfico, observou-se presença de sombra acústica posterior, no músculo semitendinoso do MPE, podendo estar relacionada à calcificação muscular. Com os achados, optou-se por realizar tenotomia da inserção tibial do músculo semitendinoso, porém não foi obtido sucesso. Com isso, após 4 meses da primeira intervenção, foi realizada a ressecção cirúrgica da massa fibrosa no músculo semitendinoso (miectomia), sendo fixados pontos de ancoragem para auxiliar na manutenção do curativo da incisão cirúrgica. Como tratamento pós-operatório foi estabelecido antibióticoterapia 
durante nove dias, analgésico por quatro dias, anti-inflamatório não esteroidal e protetor gástrico por três dias. A fisioterapia diária, constituída de caminhadas duas vezes ao dia durante oito dias, e hidroterapia na região foram instituídas a fim de não criar aderências. Após 10 dias, foram retirados os pontos cirúrgicos e readaptou-se a fisioterapia para caminhadas que intercalavam passo e trote, fechando 21 dias de tratamento. Posteriormente a este período, o animal foi liberado para as suas atividades. A tenotomia da inserção tibial do semitendinoso é uma cirurgia que, por menos invasiva que seja, não apresenta bons resultados, pois não tem o efeito desejado de recuperação completa do passo do animal. Neste caso, a massa impediu de alguma forma que o andar retornasse por completo, sendo necessária nova intervenção cirúrgica. Outros autores propõem a miectomia do músculo afetado e liberação de possíveis adesões com outros músculos, sendo esta técnica mais invasiva porém com melhor evolução e conclusão do caso. A miectomia, neste relato, mostrou-se mais efetiva, pois permitiu que o passo do cavalo retornasse ao normal, reduzindo seu tempo de recuperação, e com retorno satisfatório às suas atividades físicas habituais.

Palavras-chave: Miopatia fibrótica. Tratamento cirúrgico. Equinos. 